\title{
VARIAÇÃO DIATÓPICA E O PROCESSO DE MUDANÇA NA VALORIZAÇÃO SOCIAL DA PALATALIZAÇÃO PROGRESSIVA EM ALAGOAS
}

\author{
Almir Almeida de OLIVEIRA* \\ Alan Jardel de OLIVEIRA**
}

- RESUMO: Investiga-se a palatalização progressiva das oclusivas alveolares precedidas de /j/, como mui[ty]o e doi[d子]o em Alagoas, a partir de pressupostos teórico-metodológicos da sociolinguística variacionista. Objetiva-se analisar a distribuição diatópica da palatalização e as pressões sociais e linguísticas no processo. Analisam-se 4.046 ocorrências em entrevistas de 168 falantes de 7 cidades alagoanas, utilizando-se regressão logística multinível. Conclui-se que o processo é diatopicamente condicionado, ampliando-se do oeste para o leste e nordeste do estado. Conclui-se que o processo é inversamente proporcional à escolaridade e que a interferência da escolarização cresce na medida em que diminui a idade do falante, revelando um processo de mudança na valorização social da palatalização. Há indícios de que, apesar de ser significativamente mais produtiva em Alagoas, a palatalização não deve expandir-se ao longo do tempo, devido a pressões sociais. Em relação às variáveis linguísticas, o processo é favorecido no interior da palavra, apesar de também ocorrer na fronteira de itens lexicais. A vogal seguinte favorecedora é a vogal /i/, o que revela a interferência da dupla presença do traço [+coronal] nos ambientes adjacentes. A ausência do vozeamento na consoante alvo e a atonicidade da sílaba também favorecem a palatalização.

- PALAVRAS-CHAVE: Sociolinguística Variacionista. Variação fonético-fonológica em Alagoas. Palatalização progressiva.

\section{Introdução}

Neste trabalho, investigamos, sob a ótica da sociolinguística variacionista, a palatalização progressiva das oclusivas alveolares precedidas pela semivogal /j/ em Alagoas. Esse tipo de palatalização encontra significativa produtividade no Nordeste, havendo indícios de sua realização em quase todos os estados da região, sendo

\footnotetext{
* Universidade Federal de Alagoas (UFAL). Maceió - AL - Brasil. almir.olvieira@uneal.edu.br. ORCID: 0000-0002$3682-5480$.

*** Universidade Federal de Alagoas (UFAL). Maceió - AL - Brasil. alanjardel@gmail.com. ORCID: 0000-0002-04381352.
} 
encontradas em toda extensão Leste que vai da Bahia ao Rio Grande do Norte (SANTOS, 1996; MOTA; ROLEMBERG, 1997; HENRIQUE; HORA, 2012; SOUZA NETO, 2014; OLIVEIRA, A. A., 2017).

O processo ocorre em exemplos como:

1. "Teve ['mũ̃̃̃t $\left.\int \mathfrak{e}\right]$ violência" (muita) - AR18M06'

2. "Pelo [kuI'dzado]" (cuidado) - SM64M02

3. "Meu pai [tfã' bẽ̃̃]" (também) - PE51F11

4. "Trabalhei ['dzues] vezes" (duas) - DE51M05

O foco deste trabalho é investigar a distribuição diatópica da palatalização em falares alagoanos e as pressões sociais e linguísticas no processo.

Esse tipo de palatalização tem sido mais produtiva nas áreas periféricas das grandes cidades (SOUZA NETO, 2014; MOTA; ROLEMBERG, 1997; OLIVEIRA; OLIVEIRA; PAULA, 2018) e com valoração social negativa, sendo evitada pelas mulheres, pelos mais jovens e mais escolarizados.

O maior índice de produtividade desse tipo de palatalização foi observado na cidade Maceió com valores entre 20\% e 25\% de realização (OLIVEIRA, A. A., 2017; SANTOS, 1996), o que desperta a suposição de que aspectos geográficos são relevantes para o processo e de que, em Alagoas, a realização das variantes palatalizadas é mais frequente.

Algumas questões são norteadoras deste estudo:

a) Qual a interferência de aspectos geográficos na palatalização em Alagoas?

b) O processo é sensível ao aumento da escolarização?

c) O processo é socialmente estigmatizado em falares alagoanos?

d) Trata-se de um processo de mudança linguística em progresso?

e) Como os fatores internos da língua atuam no processo de palatalização?

\section{Metodologia}

Neste estudo, adotamos a proposta teórico-metodológica da sociolinguística variacionista, apresentada principalmente em Labov (2008) para a análise da variação e da mudança linguística, a qual prevê a identificação de um processo variável em uma comunidade de fala, a seleção de informantes, a coleta e análise de entrevistas e a análise quantitativa da variação em busca dos fatores que interferem no processo de variação.

Os dados analisados pertencem ao projeto 'PORTAL - Variação linguística no português alagoano ${ }^{2}$ (OLIVEIRA, A. J., 2017). Analisamos dados de 7 cidades alagoanas

\footnotetext{
Essa codificação traz informações sobre cidade, idade, sexo e escolaridade do informante.

Projeto financiado pelo CNPq (406218/2012-9) e aprovado pelo Comitê de Ética da Universidade Federal de Alagoas, parecer $\mathrm{n}^{\circ} 621.763$.
} 
(Maceió, Arapiraca, Delmiro Gouveia, Santana do Ipanema, Palmeira dos Índios, União dos Palmares e São Miguel dos Campos), cada uma pertencente a uma microrregião do estado (há 13 microrregiões em Alagoas).

A amostra desta pesquisa foi constituída por 168 participantes, 24 por cidade pesquisada. Os critérios de inclusão foram (1) ter nascido no município, (2) não ter se ausentado do município por mais de 10 anos e (3) ter ambos os pais nascidos também no município (preferencialmente). A amostragem foi não probabilística utilizando-se a técnica denominada "bola de neve", no qual os participantes foram selecionados por indicação de amigos ou conhecidos. Foram abordadas pessoas não conhecidas do entrevistador, mas que fossem conhecidos de alguém que o entrevistador conhecesse. A amostra por cidade foi composta por cotas, considerando as variáveis sociais sexo (masculino e feminino), faixa etária (entre 18 e 30 anos, entre 40 e 55 anos e acima de 65 anos) e escolaridade (menos de 9 anos e mais de 11 anos).

Os dados da pesquisa foram coletados por meio de entrevistas do tipo "história de vida", definida por Chizzotti (2011) como "um relato retrospectivo da experiência pessoal de um indivíduo, oral ou escrito, relativo a fatos e acontecimentos que foram significativos e constitutivos de sua experiência vivida" (CHIZZOTTI, 2011, p. 101). Além desse tipo de relato, buscamos também a opinião dos participantes em relação a temas polêmicos. O intuito foi permitir entrevistas que contenham tipos textuais diversos, indo do narrativo (com perguntas do tipo "conte um acontecimento importante da sua infância na escola?"), ao descritivo (com perguntas do tipo "como era a casa em que você morava quando tinha 10 anos?") e ao argumentativo (com perguntas do tipo "o que você pensa sobre casamento entre pessoas do mesmo sexo?"). Um roteiro prédefinido de perguntas, memorizadas pelo entrevistador, foi utilizado. Os participantes foram informados de que a conversa seria sobre memórias da infância, memórias recentes e de opiniões sobre temas polêmicos. A fim de buscarmos a diminuição do monitoramento estilístico, informávamos que o objetivo das perguntas era o de verificar a capacidade do participante de lembrar-se de fatos do passado antigo e recente com a maior quantidade de detalhes possível e saber sua opinião sobre certos temas polêmicos.

Para a gravação, foi utilizado um gravador de voz da marca TASCAM, modelo DR-100. As gravações foram realizadas em formato .wav, com taxa de amostragem de 24bits e resolução de $48 \mathrm{kHz}$. Utilizou-se também um microfone headset condensador cardióide unidirecional da marca Arcano, modelo WZ-1000. As gravações tiveram duração entre 9 e 11 minutos.

As entrevistas foram transcritas de acordo com a ortografia padrão e as transcrições foram feitas com o software PRAAT, o que possibilitou a sincronização entre áudio e transcrição. Os intervalos no PRAAT foram criados em função das pausas (silêncio maior ou igual a $200 \mathrm{~ms}$ ). Foram criados 3 tiers: para falas do documentador; para a fala do participante e para 'outros', onde se registraram falas de terceiros ou outros sons. A codificação dos colaboradores se deu da seguinte forma: o participante AR25F10 era morador da cidade de Arapiraca (AR), tinha 25 anos, era do sexo feminino (F) e tinha 10 anos de escolaridade. 
A seleção das ocorrências nos dados foi feita de forma automática, utilizando recursos de editores de textos (busca e destaque de sequências $s t, s d, i t, i d$ ). Todas as ocorrências foram analisadas acusticamente (com análise de espectrogramas e oscilogramas) com o objetivo de classificar de forma mais objetiva as variantes.

A variável dependente do estudo é a alternância entre oclusivas alveolares /t/ e /d/ e as africadas [ $\mathrm{t}]$ ] e [d3] pelo processo de palatalização progressiva em contexto precedido de semivogal /j/, como em itens lexicais do tipo 'muito' e 'doido'.

As variáveis sociais investigadas foram: sexo/gênero (masculino ou feminino); idade e escolaridade (analisadas como variáveis contínuas); e a localidade geográfica, sendo entrevistados falantes de cidades de diferentes regiões do estado: Arapiraca, Delmiro Gouveia, Maceió, Palmeira dos Índios, São Miguel dos Milagres, Santana do Ipanema e União dos Palmares.

As variáveis linguísticas investigadas foram: a vogal seguinte, que refere-se à vogal após a oclusiva (muita , oitenta, noitẹ, Feitosa, oito); o tipo de oclusiva, que diz respeito à natureza sonora da consoante (cuidar e muițo); a posição no item lexical, que trata da presença das consoantes oclusivas em posição interna da palavra, como em construções do tipo "muito e doido", ou em posição de fronteira, como em "meu pai também" e "trabalhei duas vezes"; e a tonicidade, que refere-se à presença ou ausência de acento na sílaba que contém a consoante alvo: tônica, como em ajeitar e átono, como em oitocentos e muito. Também foram analisadas como variáveis de nível mais agregado o item lexical e o indivíduo.

Para a análise quantitativa, utilizamos métodos inferenciais de análise estatística (tabelas de contingência, testes univariados e multivariados e métodos de regressão multinível). A estimação dos efeitos associados às variáveis independentes foi feita utilizando-se modelos de regressão logística multinível, um modelo multivariado que controla efeitos de variáveis mais agregadas. Os dados analisados neste trabalho possuem estrutura hierárquica já que as observações podem ser agrupadas segundo os indivíduos que as produziram e os itens lexicais. A estimativa do quanto da variabilidade observada pode ser explicada pelos níveis mais agregados (indivíduo e item lexical) foi obtida pelo coeficiente de correlação intraclasse (CCI).

Dois testes estatísticos foram utilizados: o teste da razão da máxima verossimilhança (TRMV) e o teste de Wald (TW). O TRMV analisa a significância estatística entre variáveis independentes, permitindo identificar variáveis independentes estatisticamente significativas e hierarquizar tais variáveis; o TW analisa a significância estatística entre fatores no interior das variáveis independentes, permitindo identificar fatores que apresentam efeitos estatisticamente diferentes da média dos efeitos dos fatores em uma variável independente (peso relativo $=0,50$ ).

A hipótese nula do TRMV é a de que o efeito de uma variável independente em um modelo de regressão é igual a 0 . A hipótese alternativa é a de que o efeito de tal variável é diferente de 0 . A significância do teste mede a probabilidade de cometermos um erro ao negarmos a hipótese nula, sendo a hipótese nula verdadeira. Quanto menor a significância no TRMV, maior o poder explicativo da variável independente 
sobre a variável dependente. No Varbrul e no GoldVarb (softwares tradicionalmente utilizados na análise da variação linguística), o TRMV é utilizado nas rotinas stepup e step-down. Neste trabalho, fizemos a seleção e a hierarquização das variáveis estatisticamente significativas utilizando um método semelhante ao step-down. Todas as variáveis independentes foram incluídas no modelo. As variáveis foram retiradas uma a uma considerando a maior significância no TRMV. O modelo final contém somente variáveis que apresentam significância $<0,05$. A hierarquização das variáveis estatisticamente significativas foi feita pela significância estatística de cada variável incluída no modelo final. O TRMV também foi utilizado para testar a interação entre variáveis sociais.

A hipótese nula do teste de Wald é a de que o efeito de um fator em uma variável independente é igual à média dos efeitos dos fatores dessa variável. A hipótese alternativa é a de que o efeito de tal fator é diferente da média dos efeitos dos fatores. Da mesma forma, a significância do TW mede a probabilidade de cometermos um erro ao negarmos a hipótese nula, sendo a hipótese nula verdadeira. Quanto menor a significância no TW, maior a diferença entre o efeito de um fator e a média dos efeitos dos fatores. No Varbrul e no GoldVarb, a média dos efeitos dos fatores é dada pelo que se chama, tradicionalmente, de efeito neutro (peso relativo igual a 0,50 ). O TW permite verificar se o efeito de um fator é estatisticamente diferente do efeito neutro. Tal teste é bastante útil para pesos relativos próximos de 0,50 .

Neste trabalho, a análise estatística foi feita com o auxílio do software R, utilizando os pacotes 'gmodels' (para gerar tabelas de contingência), 'lme4' (para regressão logística multinível, TRMV e TW), visreg (para gráficos de interação), DAAG, para o teste de multicolinearidade.

\section{Resultados e discussão}

Foram identificadas 4.046 ocorrências de contextos propícios à palatalização, das quais 844 (20,9\%) foram palatalizadas. Mota e Rolemberg (1997) observaram 2,4\% desse tipo de palatalização em Salvador-BA; Souza Neto, 6\% em Aracaju; Henrique e Hora (2012), 10,5\% em João Pessoa-PB; e Oliveira, A. A. (2017), 20,4\% em Maceió, o que nos permite afirmar que a palatalização progressiva das oclusivas alveolares é mais frequente em Alagoas do que em outros estados pesquisados no Nordeste.

Para nossa análise, o passo seguinte foi o ajuste do modelo de regressão, o qual permitiu identificar as variáveis estatisticamente significativas e os fatores que têm efeito sobre a palatalização regressiva. O modelo foi ajustado utilizando-se o teste da razão da máxima verossimilhança, testando-se, em um modelo multivariado de regressão logística multinível (tendo como variáveis de nível mais agregado o indivíduo e o item lexical), as variáveis independentes linguísticas tonicidade, posição no item lexical, tipo de consoante e vogal seguinte e as variáveis sociais sexo/gênero, idade, escolaridade e cidade, assim como as possíveis interações entre variáveis. O modelo 
final foi composto pelas variáveis independentes tonicidade, posição no item lexical, tipo de consoante, vogal seguinte, cidade e pela interação entre idade e escolaridade e pelas variáveis de nível agregado indivíduo e item lexical. Somente a variável sexo/ gênero foi excluída do modelo. As tabelas a seguir apresentam os resultados para as variáveis independentes após o ajuste do melhor modelo, apresentadas na ordem da significância no TRMV.

Tabela 1 - Variáveis independentes incluídas no modelo final (estatisticamente significativas)

\begin{tabular}{|c|c|c|c|c|c|}
\hline & Total & \%palatalização & $\begin{array}{l}\text { Peso } \\
\text { Relativo }\end{array}$ & Sig, Wald & Sig.TRMV \\
\hline Cidade & & & & & $6,3 e-08$ \\
\hline $\begin{array}{l}\text { São Miguel dos } \\
\text { Milagres }\end{array}$ & 546 & 32,8 & 0,68 & 0,002 & \\
\hline União dos Palmares & 569 & 25,3 & 0,62 & 0,046 & \\
\hline Maceió & 791 & 25,9 & 0,54 & 0,441 & \\
\hline Santana do Ipanema & 385 & 22,6 & 0,53 & 0,702 & \\
\hline Arapiraca & 603 & 19,2 & 0,52 & 0,807 & \\
\hline Palmeira dos Índios & 440 & 16,6 & 0,51 & 0,827 & \\
\hline Delmiro Gouveia & 712 & 5,6 & 0,16 & $<0,001$ & \\
\hline Idade * Escolaridade $^{3}$ & & & & & $1,8 \mathrm{e}-06$ \\
\hline Escol aridade & & & & $<0,001$ & \\
\hline Idade & & & & 0,084 & \\
\hline Escolaridade*Idade & & & & 0,033 & \\
\hline Posição no item lexical & & & & & $8,3 e-06$ \\
\hline interno & 3513 & 23,4 & 0,68 & $<0,001$ & \\
\hline fronteira & 533 & 4,3 & 0,32 & $<0,001$ & \\
\hline Vogal seguinte & & & & & $3,7 e-05$ \\
\hline $\mathrm{i}$ & 413 & 19,6 & 0,63 & 0,026 & \\
\hline $\mathrm{u}$ & 2517 & 26,1 & 0,56 & 0,239 & \\
\hline $\mathrm{e}$ & 178 & 5,6 & 0,56 & 0,481 & \\
\hline o & 68 & 14,7 & 0,46 & 0,654 & \\
\hline $\mathrm{a}$ & 870 & 9,8 & 0,29 & $<0,001$ & \\
\hline Tipo de consoante & & & & & 0,0009 \\
\hline$t$ & 3528 & 23,3 & 0,63 & 0,001 & \\
\hline $\mathrm{d}$ & 518 & 4,2 & 0,37 & 0,001 & \\
\hline Tonicidade & & & & & 0,039 \\
\hline átono & 3511 & 22,8 & 0,56 & 0,043 & \\
\hline tônico & 535 & 8,4 & 0,44 & 0,043 & \\
\hline Total & 4046 & 20,9 & & & \\
\hline
\end{tabular}

Fonte: Elaboração própria. 
Tabela 2 - Variável independente excluída do

modelo final (sem significância estatística)

\begin{tabular}{lcllll}
\hline & Total & \%palaalizazão & Peso Relativo & Sig.Wald & Sig.TRMV \\
\hline Sexo/gênero & & & & & 0,745 \\
\hline Feminino & 2126 & 22,8 & $*$ & $*$ & \\
Masculino & 1920 & 18,8 & $*$ & $*$ & \\
\hline Total & 4046 & 20,9 & & & \\
\hline
\end{tabular}

Fonte: Elaboração dos autores.

Tabela 3 - Variáveis agregadas de efeito aleatório incluídas no modelo final

\begin{tabular}{lllll}
\hline & $\mathrm{n}$ & Variância & CCI & Sig.TRM \\
\hline Individuo & 168 & 1,2588 & $27,7 \%$ & $2,2 \mathrm{e}-16$ \\
Item lexical & 259 & 0,1618 & $6,2 \%$ & $6,0 \mathrm{e}-05$ \\
\hline
\end{tabular}

Fonte: Elaboração própria.

Como vemos na tabela 2, a variável "sexo/gênero" não apresentou significância estatística e, portanto, a palatalização não é significativamente diferente entre os sexos/ gêneros masculino e feminino. Esse resultado contradiz outras pesquisas realizadas sobre a palatalização progressiva das oclusivas alveolares, que têm revelado uma maior utilização das formas palatalizadas pelos membros masculinos (HENRIQUE; HORA, 2012; SOUZA NETO, 2014; OLIVEIRA, A.A., 2017; OLIVEIRA; OLIVEIRA; PAULA, 2018). Também não identificamos interação entre as variáveis sociais e as cidades. Isso indica que não há diferença significativa nos efeitos das variáveis sociais e suas interações entre as diversas cidades alagoanas pesquisadas neste estudo.

A variável com maior significância foi a variável “indivíduo” (tabela 3). Isso indica que um percentual alto da variabilidade $(27,7 \%)$ pode ser explicado pela variação entre os indivíduos, independente da cidade, do sexo/gênero, da idade e da escolaridade, todas controladas no modelo. Podemos afirmar que aspectos não controlados neste estudo, relacionados aos indivíduos, interferem na variabilidade. Entretanto, mesmo não tendo ciência de tais aspectos, o controle do indivíduo como um nível agregado permite que o resultado das variáveis sociais investigadas seja mais confiável e reflita melhor a realidade observada.

O resultado para a variável "item lexical” (tabela 3 ) nos permite afirmar que uma parte reduzida da variabilidade no nível linguístico $(6,2 \%)$ pode ser atribuída à variação entre os itens lexicais e que, portanto, nossas variáveis linguísticas investigadas (a tonicidade, a posição no item lexical, a vogal seguinte e o tipo de consoante) explicam bem o processo do ponto de vista de seus condicionadores linguísticos. Vejamos a seguir a análise dessas variáveis linguísticas, da interação entre idade e escolaridade e da variável cidade.

Ao analisarmos os resultados da variável cidade na tabela 1, é possível observar, com base na significância do teste de Wald, três grupos de cidades que apresentam diferentes comportamentos na realização da palatalização. São Miguel dos Milagres 
e União dos Palmares favorecem o processo ( $\mathrm{PR}=0,68$ e 0,62, respectivamente); Maceió, Santana do Ipanema, Arapiraca e Palmeira dos Índios não apresentam efeito estatisticamente diferente do efeito médio ( $\mathrm{PR}=0,54,0,53,0,52$ e 0,51 , respectivamente); Delmiro Gouveia desfavorece a palatalização $(\mathrm{PR}=0,16)$. Vejamos o gráfico a seguir:

Gráfico 1 - Efeito da variável cidade na palatalização

das oclusivas alveolares em Alagoas ${ }^{4}$

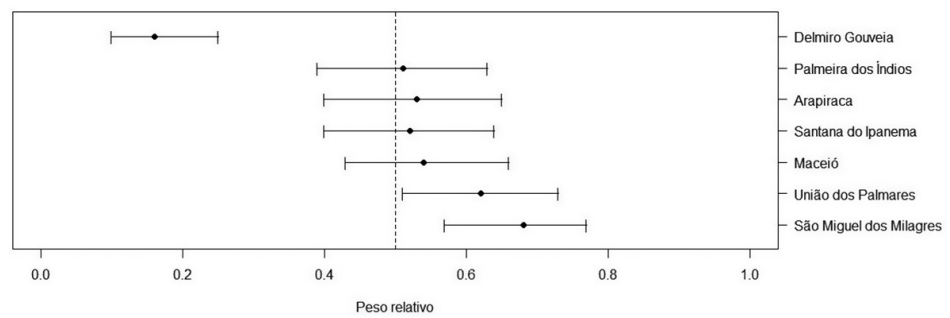

Significância da variável: (6,3e-08)

Fonte: Elaboração própria.

A partir desse resultado, podemos inferir três regiões da palatalização em Alagoas: o oeste, o nordeste e uma região que agrega o centro e o meio leste, a qual denominaremos centro-leste. Para testarmos o efeito dessas regiões, criamos uma nova variável região com três categorias: oeste (Delmiro Gouveia), centro-leste (Maceió, Santana do Ipanema, Arapiraca e Palmeira dos Índios) e nordeste (São Miguel dos Milagres e União dos Palmares). Em seguida, utilizando o TRMV, testamos a diferença entre as variáveis cidade e região nos modelos ajustados. O resultado foi uma significância de 0,949 , o que significa que os modelos são praticamente idênticos e que, portanto, o modelo que melhor explica a variabilidade é o modelo mais simples, aquele que contém a variável região. A tabela a seguir apresenta os resultados dessa variável:

Tabela 4 - Efeito da variável região na palatalização

das oclusivas alveolares em Alagoas

\begin{tabular}{llllll}
\hline & Total & \%palatalização & $\begin{array}{l}\text { Peso } \\
\text { Relativo }\end{array}$ & Sig,Wald & Sig.TRMV \\
Região em Alagoas & & & & & $3,4 \mathrm{e}-10$ \\
Nordeste & 1.115 & 29,0 & 0,72 & $<0,001$ & \\
Centro-leste & 2.219 & 21,7 & 0,60 & 0,007 & \\
Oeste & 712 & 5,6 & 0,21 & $<0,001$ & \\
\hline TOTAL & 4.046 & 20,9 & & & \\
\hline
\end{tabular}

Fonte: Elaboração própria.

4 Neste gráfico, e nos demais que seguirão o mesmo modelo, os pontos para cada fator representam o peso relativo e os traços nas extremidades da reta indicam o intervalo de confiança, dentro do qual está $95 \%$ das estimativas prováveis (o que nos leva a $5 \%$ de erro e a um nível de significância de 0,05 ). Quando a linha cruza o PR de 0,50 , significa que não podemos dizer que o efeito do fator difere-se do efeito médio (ou ponto neutro) com uma significância de 0,05 . 
Considerando os resultados da análise, concluímos que há um efeito diatópico na palatalização em Alagoas, aumentando do oeste para o leste e amplificando-se na região nordeste do estado, como podemos observar no mapa a seguir:

Mapa 1 - Distribuição da palatalização das oclusivas alveolares em Alagoas

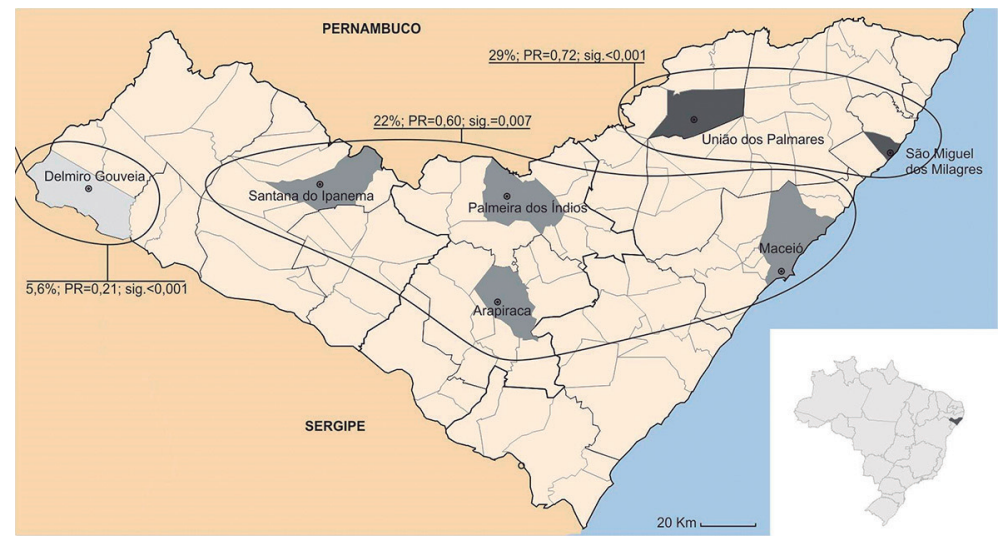

Fonte: Elaboração própria.

Nossos resultados comprovam a hipótese inicial de que a palatalização é geograficamente condicionada e tem uma direção no estado de Alagoas (do oeste para o leste).

Vejamos a seguir o efeito da idade e da escolaridade na palatalização das oclusivas alveolares.

Gráfico 2 - Efeito da interação entre idade e escolaridade na palatalização das oclusivas alveolares em Alagoas

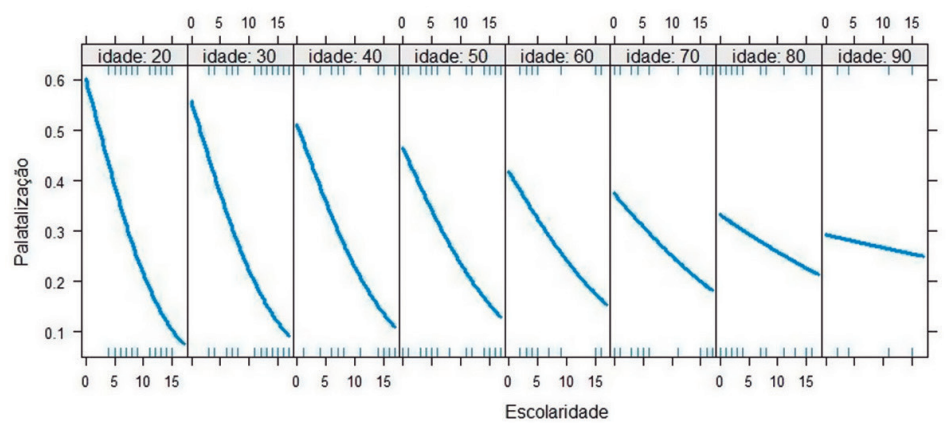

Significância da variável: $(1,8 \mathrm{e}-06)$

Fonte: Elaboração própria. 
As linhas no gráfico acima representam o efeito da escolaridade em diversas faixas etárias. Observamos que, em todas as idades, há um efeito inversamente proporcional da escolaridade, o que indica que quanto maior o nível de escolaridade, menor o uso da palatalização das oclusivas. Vemos também que, com o aumento da idade, diminuise a inclinação da reta da escolaridade, o que indica que a escolaridade tem seu efeito diminuído com o aumento da idade.

É razoável supor que o comportamento linguístico dos falantes indica que a palatalização vem adquirindo, ao longo dos anos, um valor social negativo e que a escola é o principal ambiente social de difusão de tal valor. Esse resultado relaciona-se com o obtido em Oliveira, Oliveira e Paula (2018) em Maceió, em que ficou expresso que o efeito da escolaridade sobre o falante era diferente a depender de sua idade, visto que os mais escolarizados foram os maiores favorecedores do processo, quando jovens, e os maiores inibidores, quando idosos. Agora, vimos que tal efeito se estende a outros falares alagoanos.

Pesquisas sociolinguísticas que têm investigado a correlação entre a escolaridade e processos linguísticos variáveis geralmente se deparam com uma dupla informação social, a influência do nível de escolarização na escolha linguística do colaborador e indícios de sua classe social, uma vez que a tendência é que o nível social do colaborador acompanhe seu desenvolvimento escolar.

As escolas desenham de forma desigual os recursos sociais e culturais dos membros da sociedade. Como as escolas usam as estruturas linguísticas, padrões de autoridade e currículos da cultura dominante (isto é, das classes média e alta), há um alinhamento natural entre as famílias de classe média e a cultura da escola. (CREGAN, 2008, p. 12, tradução nossa). ${ }^{5}$

Ao investigarmos a relação entre a escolaridade e a realização de variantes linguísticas podemos verificar a influência da valoração social nos usos linguísticos dos falantes, visto que o ambiente educacional contribui com o fomento das formas cultas da língua, na medida em que estigmatiza outras formas concorrentes, atribuindolhes valores negativos.

Apesar de identificarmos um efeito da idade na palatalização, tal efeito não parece estar relacionado a uma mudança linguística em progresso, pelo menos por enquanto. O que temos é uma forte influência da escola na diminuição da variante palatal entre falantes mais jovens. Podemos afirmar que a palatalização progressiva das oclusivas alveolares precedidas de / $\mathrm{j} /$ sofre pressões sociais negativas e se encontra em crescente resistência nos ambientes educacionais, afetando principalmente os mais jovens.

Original: "Because schools use the linguistic structures, authority patterns, and curricula of the dominant culture (i.e. that of the middle and upper classes), there is a natural alignment between middle-class families and the culture of the school" (CREGAN, 2008, p. 12). 
Vejamos a seguir a análise das variáveis independentes linguísticas investigadas neste estudo.

A variável posição no item lexical diz respeito à posição do processo em relação aos itens lexicais; se é interno ao item e, portanto, /j/ pertence ao mesmo item (como vaidoso e aceita); ou se está na fronteira, sendo /j/ o segmento final do item lexical anterior (como peguei duas e foi tomar). Os resultados expressos na tabela 1 demonstram que o contexto fronteira é altamente desfavorecedor da palatalização progressiva (4,3\% e $\mathrm{PR}=0,32)$; ao contrário do contexto interno $(23,4 \%$ e $\mathrm{PR}=0,68)$.

Gráfico 3 - Efeito da variável posição no item lexical na palatalização das oclusivas alveolares em Alagoas

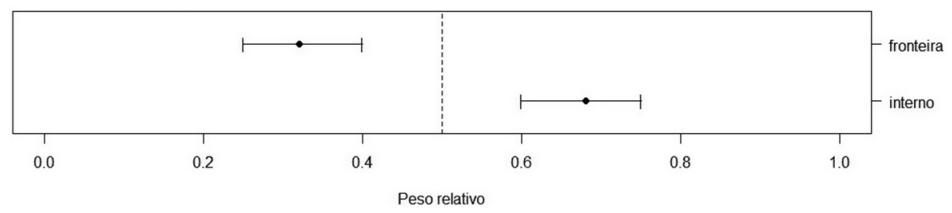

Significância da variável: $(8,3 e-06)$

Fonte: Elaboração própria.

A variável posição no item lexical revelou que, embora seja possível a palatalização em limite de palavras lexicais, essa probabilidade diminui quando as consoantes oclusivas estão em fronteira para além da palavra fonológica. Podemos dizer, então, que o processo é altamente favorecido no domínio da palavra fonológica, porém não é bloqueado em domínios acima deste.

A variável vogal seguinte diz respeito à vogal posterior às consoantes t/d: a (muita), e (dele), i (jeitinho), o (aceitou), u (tuddo). Os resultados expressos na tabela 1 e no gráfico 4 demonstram que a palatalização é favorecida pela vogal seguinte $\mathrm{i}(\mathrm{PR}=0.63)$ e desfavorecida pela vogal seguinte a $(\mathrm{PR}=0.29)$. As demais vogais não apresentam diferença estatística em relação ao efeito médio. 
Gráfico 4 - Efeito da variável vogal seguinte na palatalização das oclusivas alveolares em Alagoas

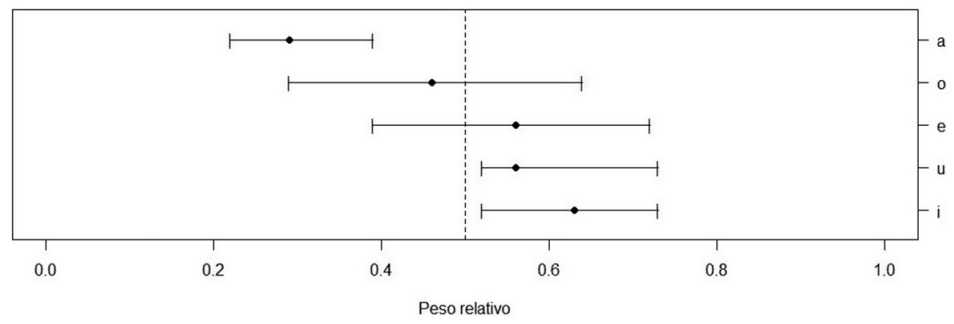

Significância da variável: (3,7e-05)

Fonte: Elaboração própria.

Uma vez que o traço [+coronal] é o gatilho universal do processo de palatalização (NEUSCHRANK; MATZENAUER, 2012), é razoável pensar que a sua dupla presença, tanto no contexto precedente, com a semivogal $/ \mathrm{j} /$, quanto no seguinte, com a vogal /i/, acarreta um duplo gatilho para o processo, mostrando que neste contexto há probabilidades significativamente maiores de ocorrer a palatalização.

A variável tipo de consoante diz respeito à consoante alvo do processo, /t/ ou /d/ (muito, doido). Os resultados apresentados na tabela 1 e no gráfico 5 demonstram que a probabilidade de ocorrência da palatalização é bem maior quando a consoante é /t/ $(23,3 \%$ e $\mathrm{PR}=0,63)$ do que quando é $/ \mathrm{d} /(4,2 \%$ e $\mathrm{PR}=0,37)$.

Gráfico 5 - Efeito da variável tipo de consoante na palatalização das oclusivas alveolares em Alagoas

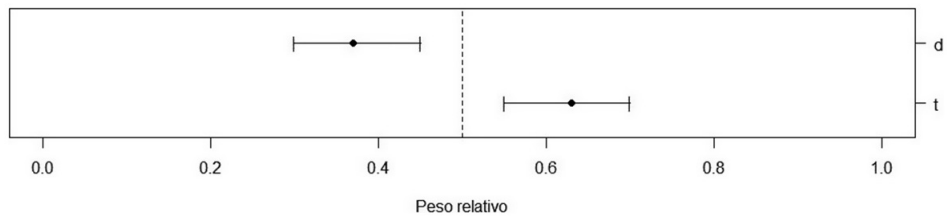

Significância da variável: $(0,0009)$

Fonte: Elaboração própria.

O resultado observado está de acordo outros trabalhos que demonstram o favorecimento de /t/ no processo (MOTA; ROLEMBERG, 1997; SANTOS, 1996; HENRIQUE; HORA, 2012; SOUZA NETO, 2014; OLIVEIRA, A. A., 2017). É possível que o favorecimento da consoante / $t$ / esteja associado à ausência de vibração das pregas vocais, o que faz com que tal consoante seja articulada com menor energia. Tal razão é apontada em Hora (1990), Abaurre e Pagotto (2002) e Battisti e Guzzo (2009). 
A variável tonicidade refere-se à presença ou ausência de acento na sílaba que contém a consoante alvo t/d, como em muito e oitocentos (átonos) e prefeitura (tônico). Os resultados apresentados na tabela 1 e no gráfico 6 demonstram que a palatalização tem maior probabilidade de ocorrer em sílabas átonas $(22,8 \%$ e $\mathrm{PR}=0,56)$ do que em sílabas tônicas $(8,4 \%$ e $\mathrm{PR}=0,44)$.

Gráfico 6 - Variável tonicidade e a palatalização das oclusivas alveolares em Alagoas

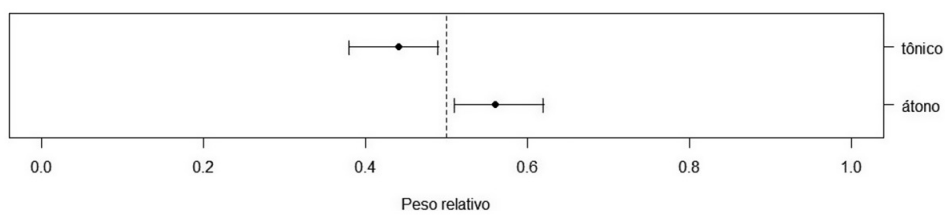

Significância da variável: $(0,039)$

Fonte: Elaboração própria.

Esse resultado confirma a hipótese de que a sílaba átona favorece o processo. Acreditamos, em consonância com Bisol (1991), que o critério de saliência atesta que as formas inovadoras em sílabas menos proeminentes tendem a ter mais sucesso que as inovações em sílabas fortes.

A regra incipiente mostra preferência por realizações sensíveis que passam despercebidas, isto é, para posições menos complexas na estrutura da sílaba ou para menor força prosódica, ou para segmentos fonológicos menos complexos e representações subjacentes menos abstratas. Diminuindo o efeito externo, isso impede a crítica de comportamento linguístico incomum, mais prejudicial para a expansão de uma regra e sua consequente generalização. (BISOL, 1991, p. 117).

Assim, é possível explicar como o processo de palatalização progressiva das oclusivas alveolares apresenta uma tendência de realização distinta dependendo da tonicidade da sílaba em que aparecem as consoantes-alvo e porque a sílaba tônica diminui a probabilidade de ocorrência do processo de palatalização.

\section{Conclusão}

Duas conclusões merecem destaque neste trabalho: (1) Há diferenças regionais importantes na palatalização progressiva em Alagoas, dado o aumento da incidência do processo indo do oeste para o leste e ampliando-se no nordeste do estado; (2) O processo ocorre menos na medida em que se aumenta a escolaridade e, mais interessante, 
a interferência da escolarização cresce na medida em que se diminui a idade do falante, o que revela um processo de mudança na valorização social da palatalização.

Há ainda outros avanços no estudo. O controle das variáveis agregadas indivíduo e item lexical por meio do uso de modelos de regressão multinível permitiu maior confiabilidade na identificação dos efeitos associados às variáveis independentes linguísticas e sociais, isolando eventuais idiossincrasias relacionadas a elementos de tais variáveis agregadas.

Apesar de o processo ser significativamente mais produtivo em Alagoas (em relação a outras regiões do nordeste brasileiro), é provável que, devido às pressões sociais, não identifiquemos um aumento da sua realização ao longo do tempo.

Em relação às variáveis linguísticas, concluímos que o processo tem probabilidade mais alta de ocorrer no interior da palavra, apesar de também ocorrer na fronteira de itens lexicais. A vogal seguinte favorecedora é a vogal /i/, o que revela o aumento da probabilidade da palatalização diante da dupla presença do traço [+coronal] nos ambientes adjacentes. A ausência do vozeamento na consoante alvo e a atonicidade da sílaba também contribuem significativamente para a incidência da palatalização.

OLIVEIRA, A.; OLIVEIRA, A. Diatopic variation and the change process in the social valorization of progressive palatalization in Alagoas. Alfa, São Paulo, v. 65, 2021.

- ABSTRACT: we investigate the progressive palatalization of alveolar occlusives preceded by /j/, as mui [t] o and doi [d]] in Alagoas, based on theoretical-methodological assumptions of the variational sociolinguistics. We aim to analyze the diatopic distribution of palatalization and the social and linguistic pressures in the process. We analyzed 4,046 occurrences in interviews of 168 speakers from 7 cities in Alagoas, using multilevel logistic regression. We conclude that the process is diatopically conditioned, extending from the west to the east and northeast of the state. It is concluded that the process is inversely proportional to schooling and that the interference of schooling increases as the speaker's age decreases, revealing a process of change in the social value of palatalization. There is evidence that, although it is significantly more productive in Alagoas, the palatalization should not expand over time due to social pressures. Regarding linguistic variables, the process is favored within the word, although it also occurs at the border of lexical items. The next favoring vowel is the vowel $/ i /$, which reveals the interference of the double presence of the [+ coronal] trace in adjacent environments. The absence of voicing in the target consonant and syllable atonicity also favor palatalization.

- KEYWORDS: Sociolinguística Variacionista. Phonological-phonetic variation in Alagoas. Progressive palatalization. Alagoas. 


\section{REFERÊNCIAS}

ABAURRE, M. B. M.; PAGOTTO, E. G. A palatalização das oclusivas dentais no português do Brasil. In: NEVES, M. H. de M. (org.). Gramática do português falado VII: novos estudos descritivos. Campinas: Ed. da Unicamp, 2002. p. 557-602.

BATTISTI, E.; GUZZO, N. B. Palatalização das oclusivas alveolares: o caso de Chapecó. In: BISOL, L.; COLLISCHONN, G. (org.). Português no sul do Brasil: variação fonológica. Porto Alegre: EDIPUCRS, 2009. p.114-140.

BISOL, L. Palatalization and its variable restriction. International Journal of Sociology of Language, Mouton, n. 89, p. 107-124, 1991.

CHIZZOTTI, A. Pesquisa em ciências humanas e sociais. 4 ed. São Paulo: Vozes, 2011.

CREGAN, A. Sociolinguistic Perspectives on the Context of Schooling in Ireland: parent perceptions. Working Paper Series 08/04, Combat Poverty Agency, v.II, August 2008.

HENRIQUE, P.; HORA, D. Um olhar sobre a palatalização das oclusivas dentais no vernáculo pessoense. In: JORNADA NACIONAL DO GRUPO DE ESTUDOS LINGUÍSTICOS DO NORDESTE, 24., 2012, Natal, RN. Anais [...] Natal: EDUFRN, 2012. p. $150-161$.

HORA, D. A palatalização das oclusivas dentais: variação e representação não-linear. 1990. Tese (Doutorado em Letras) - Instituto de Letras, PUC-RS, Porto Alegre, 1990.

LABOV, W. Padrões Sociolinguísticos. Trad. Marcos Bagno. São Paulo: Parábola, 2008. Original de 1972.

MOTA, J.; ROLEMBERG, V. Variantes africadas palatais em Salvador. In: HORA, D. (org.). Diversidade Linguística no Brasil. João Pessoa: Ideia, 1997. p. 131-140.

NEUSCHRANK, A.; MATZENAUER, C. L. B. A palatalização na diacronia do PB: o surgimento dos segmentos palatais à luz de teoria fonológica. Linguística, Montevidéu, v. 27, p.18-46, jun. 2012. Disponível em: http://www.scielo.edu.uy/scielo. php?script=sci_arttext\&pid=S2079-312X2012000200003. Acesso em: 22 jun. 2021.

OLIVEIRA, A. A. Processos de Palatalização das oclusivas alveolares em Maceió. 2017. Tese (Doutorado em Letras e Linguística) - Programa de Pós-Graduação em Letras e Linguística, Universidade Federal de Alagoas, Maceió, 2017.

OLIVEIRA, A. J. Projeto PORTAL: variação linguística no português alagoano. Disponível em: http://www.portuguesalagoano.com.br. Acesso em: 22 jun. 2017.

OLIVEIRA, A. A.; OLIVEIRA, A. J.; PAULA, A. S. Palatalização das oclusivas alveolares [t] e [d] com a semivogal [j] em contexto anterior na cidade de Maceió. Revista Leitura, Maceió, v. 1, n. 60, p. 102-122, jan./jun. 2018. 
SANTOS, L. F. Realização das oclusivas /t/ e/d/na fala de Maceió. 1996. Dissertação (Mestrado em Letras e Linguística) - Programa de Pós-Graduação em Letras e Linguística, Universidade Federal de Alagoas, Maceió, 1996.

SOUZA NETO, A. F. Realizações dos fonemas /t/ e /d/ em Aracaju - Sergipe. Aracaju: Ed. da UFS, 2014.

Recebido em 19 de fevereiro de 2019

Aprovado em 08 de outubro de 2020 